Check for updates

Cite this: RSC Adv., 2019, 9, 36951

\title{
Effect of alkyl distribution in pyrazine on pyrazine flavor release in bovine serum albumin solution
}

\author{
Yun-Jiao Ma, $\uparrow$ Jian-Hai Wu, $\uparrow$ Xiang Li, Xian-Bing Xu, (D)* Zhen-Yu Wang, Chao Wu, \\ Ming Du and Liang Song (D) *
}

The flavor release mechanism related to the interaction of aroma compounds with proteins is still unclear. In this study, the interaction of protein with pyrazine homologues, such as 2-methylpyrazine (MP), 2,5dimethylpyrazine (DP), 2,3,5-trimethylpyrazine (TRP) and 2,3,5,6-tetramethylpyrazine (TEP), was investigated to elucidate the effect of alkyl distribution in a pyrazine ring on its flavor release in bovine serum albumin (BSA) solution ( $\mathrm{pH}$ 7.4). The results of SPME-GC-MS indicated that methyl distribution in a pyrazine ring significantly affected its release from BSA solution. The pyrazines released from BSA solution with an increasing order of MP, DP, TRP and TEP. The inhibition mechanism of alkyl-pyrazine release was further elucidated by the interaction between alkyl-pyrazines and BSA using multiple spectroscopic methods. The non-covalent interaction between alkyl-pyrazines and BSA was confirmed as the main interaction force by the value of the bimolecular quenching constant $\left(K_{\mathrm{q}}>2 \times 10^{10} \mathrm{~L} \mathrm{~mol}^{-1}\right.$ $\mathrm{s}^{-1}$ ). A decrease in the hydrophobicity of the microenvironment between the alkyl-pyrazine and BSA was detected by synchronous fluorescence spectra, which revealed that alkyl-pyrazines were mainly bound on the sites of tyrosine and tryptophan in BSA. The UV-vis absorption spectra and circular dichromatic (CD) spectrum revealed that alkyl-pyrazines could induce polarity and conformation change of BSA. The above results indicated that the structure of the flavor homologues can affect their release in food matrices.

Received 26th August 2019

Accepted 28th October 2019

DOI: $10.1039 / \mathrm{c} 9 \mathrm{ra06720e}$

rsc.li/rsc-advances necessary to understand the binding or releasing mechanism of flavor compounds in food because it is not only possible to modulate flavors, but also to improve the sensory properties of food. ${ }^{18}$ Therefore, the interaction between protein and flavor compounds was commonly investigated. The binding of proteins with flavor compounds not only depended on their intrinsic properties and conformational state of proteins, ${ }^{19,20}$ but also on the chemical property of flavor compounds. Numerous studies were carried out to elucidate the binding mechanisms of proteins with flavor compounds such as aldehydes, alcohols, ketones and esters. $^{21-23}$ However, the interaction between flavor homologues and proteins has rarely been reported.

Pyrazines were important heterocyclic flavor compounds, mainly formed during Maillard reaction ${ }^{\mathbf{2 4 , 2 5}}$ or fermentation processing. ${ }^{26,27}$ Commonly, the produced pyrazines presented the roasted flavor or the baked flavor, ${ }^{28}$ which were important for evaluating the flavor quality of foodstuff, such as vinegar, meat production, flavoring, and so on. The pyrazine structures generally contained a heterocyclic structure with two nitrogen atoms (Fig. 1A). The functional groups $\left(-R_{1},-R_{2},-R_{3}\right.$ and $\left.-R_{4}\right)$ like alkyl-, oxygenated- and acyl-groups could distribute at four carbon atom of heterocyclic structure. Recently, more than 70 different alkyl-pyrazines had been identified in nature. ${ }^{29}$ To some extent, the alkyl-pyrazines homologues exhibited the similar chemical properties, but it was still unknown that the different distributions of functional groups on a pyrazine ring
National Engineering Research Center of Seafood, School of Food Science and Technology, Dalian Polytechnic University, Dalian 116034, China. E-mail: xianbingxu@gmail.com; ryo.song@foxmail.com; Fax: +86 411 86323262; +86 411 86323453; Tel: +86411 86332275; +86 15942804820

$\dagger$ Both authors have contributed equally to this work. 
A<smiles>[R4]c1nc([R4])c([R4])nc1[R3]</smiles>

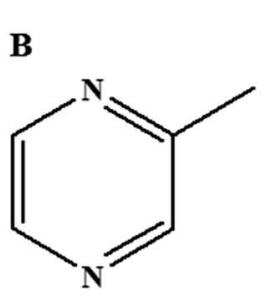

C

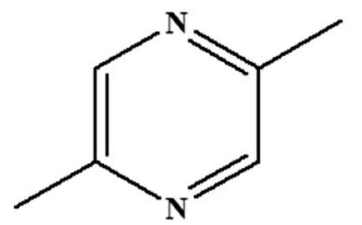

D

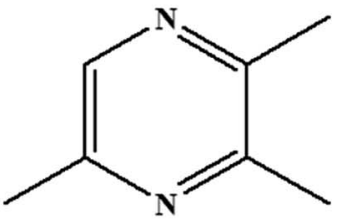

$\mathbf{E}$

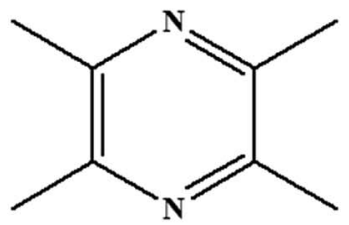

Fig. 1 Molecular structure of pyrazines family(A), 2-methylpyrazine (B), 2,5-dimethylpyrazine (C), 2,3,5-trimethylpyrazine (D) and 2,3,5,6-tetramethylpyrazine $(\mathrm{E})$.

could induce the difference in flavor release. Although the nature of interactions between pyrazines and $\beta$-lactoglobulin were theoretically calculated by $3 \mathrm{D}-\mathrm{QSAR},{ }^{30}$ an experiment study was still not performed. In this study, alkyl-pyrazines homologues with different alkyl distributions including 2-methylpyrazine (MP), 2,5-dimethylpyrazine (DP), 2,3,5trimethylpyrazine (TRP) and 2,3,5,6-tetramethylpyrazine (TEP) were selected to illustrate the effect of pyrazines homologues compounds on flavor release in food matrix.

Protein, as an essential food component, was commonly used in food industry due to its emulsification, ${ }^{31}$ foamability ${ }^{32}$ and gelation property. Protein was widely used to control flavor release or deliver flavor by bonding hydrophobic or hydrogen interacted with flavor compounds or forming the weak and unspecific binding forces. ${ }^{33,34}$ Among the food proteins, bovine serum albumin (BSA), ${ }^{21} \alpha$-lactalbumin, ${ }^{35} \beta$-lactoglobulin, ${ }^{36}$ and myofibrillar protein ${ }^{20,22}$ were usually used as food matrix to investigate the interaction mechanism between flavor compounds and protein. In the food systems, BSA has been universally applied in gel, ${ }^{37}$ delivery, ${ }^{38}$ nanoparticle ${ }^{39}$ and emulsion..$^{40}$ Compared with soy protein, ovalbumin and $\beta$ casein, BSA has been used as emulsifier for food flavor delivery. ${ }^{41}$ In addition, BSA was frequently employed as model protein for the chemical mechanism study in food system. ${ }^{42}$ Generally, BSA has domains that can specifically bind to small molecules, such as metal ions and nucleotides. ${ }^{43,44}$ In this study, BSA as the ideal model protein was selected to reveal the flavor release mechanism between pyrazines and protein in food matrix.

The aim of this study was to investigate the effect of alkyl distribution of pyrazines on flavor release from protein matrix. The flavor release rate of pyrazines was detected by SPME-GC-MS. The interaction mechanism of pyrazines with BSA was evaluated by multispectroscopic methodologies, including fluorescence quenching analysis, ultraviolet visible (UV-vis) spectrophotometry and circular dichromatic (CD) spectrum.

\section{Materials and methods}

\section{Materials}

BSA was purchased from Sangon Biotech (Shanghai, China). MP, DP, TRP and TEP were provided by Sigma-Aldrich (St. Louis, MO, U.S.A). The BSA solution $\left(15 \times 10^{-4} \mathrm{~mol} \mathrm{~L}^{-1}\right)$ was prepared in phosphate buffer solution (PBS, the concentration was $1 \times 10^{-2} \mathrm{~mol} \mathrm{~L}^{-1}$ and $\left.\mathrm{pH}=7.4\right)$ and stored at $277 \mathrm{~K}$ for experiment. The solutions $\left(1 \times 10^{-2} \mathrm{~mol} \mathrm{~L}^{-1}\right)$ of MP, DP, TRP and TEP were prepared in PBS and stored at $277 \mathrm{~K}$ for further experiments. The ultrapure water was used throughout the experiment.

\section{Solid phase micro-extraction gas chromatography mass spectrometry (SPME-GC-MS) analysis}

In this study, the manual SPME was used for collecting the volatile pyrazines. The method of GC-MS was established for the separation and identification of different kinds of pyrazines. For the SPME, the vials $(20 \mathrm{~mL})$ were filled with $1 \mathrm{~mL}$ solutions composed of a mixture of pyrazine solution $(1 \times$ $\left.10^{-5} \mathrm{~mol} \mathrm{~L}^{-1}\right)$ and BSA solution $\left(0,5,15 \times 10^{-4} \mathrm{~mol} \mathrm{~L}^{-1}\right.$, respectively). The vials were heated at $323 \mathrm{~K}$ under stirring. The extraction fiber of SPME coatings with $50 / 30 \mu \mathrm{m}$ DVB/CAR/ PDMS was inserted into the vials and extracting the head space compounds for 30 minutes. When the extraction was completed, the fiber was placed in the injection port of the GCMS system (Agilent 7890B-5977A, Agilent, U.S.A) with GC column (HP-5MS, $30 \mathrm{~m} \times 250 \mu \mathrm{m}$ ID). The time of desorption and the injection temperature were 5 minutes and $523 \mathrm{~K}$, respectively. The oven heat program began at $308 \mathrm{~K}(3$ minutes) and then was increased to $553 \mathrm{~K}$ at $283 \mathrm{~K} \mathrm{~min}^{-1}$, and maintained at $553 \mathrm{~K}$ for $5 \mathrm{~min}$. The MS with electronic impact ionization source (ionization voltage: $70 \mathrm{eV}$ ) operated in scan mode and the mass detection range was from 40 to $400 \mathrm{~m} / \mathrm{z}$. In addition, the ability of pyrazine to release from BSA is reflected by the peak area ratios (area of pyrazine with BSA/area of pyrazine without BSA). 
Fluorescence spectrometry and synchronous fluorescence spectrometry analysis

The fluorescence spectra of BSA in the presence of various concentrations of MP, DP, TRP and TEP were recorded by F2700 (Hitachi, Japan) at 300, 310 and $323 \mathrm{~K}$, the temperature was maintained by the thermostatic bath bought from (Nan Jing Xin Chen Biotechnology Co., Ltd). The excitation (EX) wavelength was $290 \mathrm{~nm}$ and the emission (EM) wavelength was recorded from 300 to $500 \mathrm{~nm}$. The synchronous fluorescence spectra were measured with the $D$-value $(\Delta \lambda)$ between excitation wavelength and emission wavelength at 15 or $60 \mathrm{~nm}$. The slit widths of EX and EM were set at $5 \mathrm{~nm}$. The quartz cell (1.0 $\mathrm{cm}$ ) was used in this experiment. The concentration of BSA was diluted into $5 \times 10^{-4} \mathrm{~mol} \mathrm{~L}^{-1}$ for this study. The concentration of MP, DP, TRP and TEP was $1 \times 10^{-2} \mathrm{~mol} \mathrm{~L}^{-1}$. The selected pyrazine solutions ( $6 \mu \mathrm{L}$ of each time, 6 times in total) were successively added into the BSA solution $(2 \mathrm{~mL}$ in volume) and tested by 10 minutes interval. The fluorescence quenching was conducted in this study by adding different concentrations $\left(0,3,6,9,12,15\right.$ and $\left.18 \times 10^{-5} \mathrm{~mol} \mathrm{~L}^{-1}\right)$ of DP, MP, TRP and TEP into BSA solution at 300,310 or $323 \mathrm{~K}$, respectively.

\section{Ultraviolet visible (UV-vis) spectrophotometry analysis}

The UV-vis absorption spectra were recorded from 200 to $500 \mathrm{~nm}$ by Lambda 35 (PerkinElmer, USA). The UV absorption spectra of BSA solution $\left(2 \mathrm{~mL}, 2 \times 10^{-6} \mathrm{~mol} \mathrm{~L}^{-1}\right)$ with pyrazines $\left(5 \times 10^{-5} \mathrm{~mol} \mathrm{~L}^{-1}\right)$ or without pyrazines were measured. In addition, the UV spectra of pyrazines solution $(2 \mathrm{~mL}, 5 \times$ $10^{-5} \mathrm{~mol} \mathrm{~L}^{-1}$ ) were also recorded. The entire experiment was conducted at room temperature $(300 \mathrm{~K})$ and the quartz cell $(1.0$ $\mathrm{cm})$ was used for trials.

\section{Circular dichromatic (CD) spectrum analysis}

The CD spectra were recorded at room temperature (300 K) under constant nitrogen flush using a CD spectropolarimeter (J1500 , Jassco, Japan), and the range of wavelength was set from 200 to $280 \mathrm{~nm}$. The scan speed was set at $100 \mathrm{~nm} \mathrm{~min}{ }^{-1}$. The bandwidth was set at $1 \mathrm{~nm}$, and the path length was $0.1 \mathrm{~cm}$ quartz cell. The concentration of BSA was $5 \times 10^{-6} \mathrm{~mol} \mathrm{~L}^{-1}$. The volume $(350 \mu \mathrm{L})$ of BSA was tested. The volume $(10 \mu \mathrm{L})$ of pyrazines $\left(1 \times 10^{-2} \mathrm{~mol} \mathrm{~L}^{-1}\right)$ was added into the BSA solution $(5 \times$ $\left.10^{-6} \mathrm{~mol} \mathrm{~L}^{-1}\right)$ for measurement.

\section{Statistical analysis}

The experimental data were presented in form of mean and standard deviation. Analysis of variance was used to determine any significant differences $(p<0.05)$ among the applied treatments by the SPSS software package (SPSS 10.0 for Windows).

\section{Results and discussion}

\section{Release of pyrazines in BSA solution}

The SPME-GC-MS and the headspace GC were applied to clarify the flavor release mechanisms. ${ }^{45}$ As shown in Fig. 2, the peak area ratios (area of pyrazine with BSA/area of pyrazine without BSA) significantly decreased with the increasing concentrations of BSA. This decrease in peak area ratio could be explained by a decrease in the amount of free pyrazine in solution after interaction with BSA. This result was consistent with the previous studies. ${ }^{46,47}$ Interestingly, the area ratio of DP (from 1 to 0.83 ), TRP (from 1 to 0.79 ) and TEP (from 1 to 0.65 ) decreased significantly, while the area ratio of MP (from 1 to 0.95) decreased slightly with the increasing concentration of BSA (the concentration ranging from 0 to $15 \times 10^{-5} \mathrm{~mol} \mathrm{~L}^{-1}$ ). The results indicated that the distribution and the number of functional groups may have an important effect on release of pyrazines in food matrix.

\section{Fluorescence quenching analysis and binding mode}

Fluorescence quenching was used to assess the decrease in quantum yield of fluorophore fluorescence induced by interactions with a variety of molecular of quenchers. ${ }^{48}$ The quenching mechanisms could be categorized as dynamic and static quenching. In general, the different temperature dependence of fluorescence quenching behavior was applied to distinguish dynamic and static quenching. ${ }^{49}$ Thus, the fluorescence quenching was investigated at different temperatures $(300,310$ or $323 \mathrm{~K})$ in this study.

To avoid the inner filter effects, fluorescence quenching experiments were performed in the linear range of SternVolmer curve. ${ }^{50}$ The Stern-Volmer equation was used to analyze the fluorescence quenching. ${ }^{51}$

$$
\frac{F_{0}}{F}=1+K_{\mathrm{q}} \tau_{0}[\mathrm{Q}]=1+K_{\mathrm{SV}}[\mathrm{Q}]
$$

where, $F_{0}$ and $F$ represented the fluorescence intensity of BSA in the absence and presence of pyrazines. Typically, the fluorescence lifetime of biopolymer $\left(\tau_{0}\right)$ was $10^{-8}$ s. $K_{\mathrm{q}}$ represented the bimolecular quenching constant, $K_{\mathrm{Sv}}$ was the quenching constant and $[\mathrm{Q}]$ was the pyrazine concentration. The value of $k_{\mathrm{q}}$ and $K_{\mathrm{SV}}$ at different temperatures corresponded to DP, MP, TP and TMP were shown in Table 1. In addition, the Stern-Volmer plot $(T=323 \mathrm{~K})$ was described in Fig. 3.

Significantly, the fluorescence intensity of BSA decreased with addition of pyrazine into BSA solution (Fig. 3A-D). The values of $K_{\mathrm{Sv}}$ in the pyrazine-BSA interaction systems were decreased with the increasing temperature and $K_{\mathrm{q}}>2 \times 10^{10} \mathrm{~L}$ $\mathrm{mol}^{-1} \mathrm{~s}^{-1}$ (Table 1). The results indicated that the interaction between pyrazines and BSA was attributed to the static quenching effect. In addition, as shown in Table 1, TRP and TEP exhibited strong interaction with BSA compared to DP, MP at same temperature. The interaction intensity of BSA with pyrazines was listed in order: MP $<\mathrm{DP}<\mathrm{TRP}<\mathrm{TEP}$, which was consistent with the GC-MS results.

The interaction forces may be the weak interaction force, such as hydrogen bonding, van der Waals force, hydrophobic effect and electrostatic interaction, which are the main interactions between a small molecule and biological macromolecule. ${ }^{52,53}$ The specific interactions can be determined based on the enthalpy change $(\Delta H)$ and entropy change $(\Delta S)$ in the 

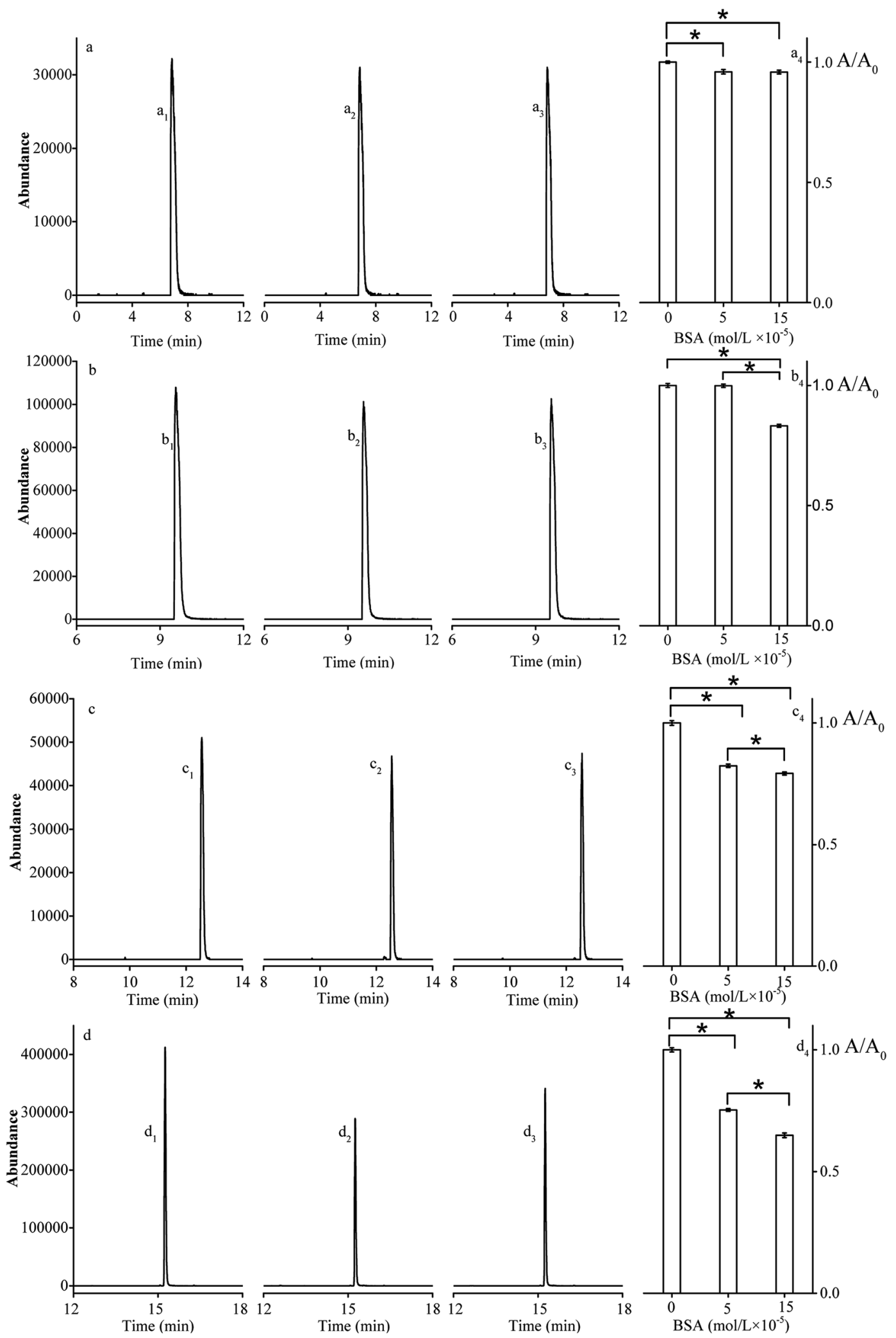

Fig. 2 The extracted ion chromatograms of 2-methylpyrazine (a), 2,5-dimethylpyrazine (b), 2,3,5-trimethylpyrazine (c) and 2,3,5,6-tetramethylpyrazine (d); the area ratio of extracted ion chromatograms $A / A_{0}$ (area of pyrazine with BSA on area of pyrazine without BSA, one-way ANOVA, Tukey's test, $* P<0.05)$ presented in $a_{4}, b_{4}, c_{4}, d_{4}$. The mixture pyrazines $\left(1 \times 10^{-5}\right.$ mol L $\left.{ }^{-1}\right)$, with BSA 0 mol L $L^{-1}\left(a_{1}, b_{1}, c_{1}, d_{1}\right), 5 \times$ $10^{-4} \mathrm{~mol} \mathrm{~L}^{-1}\left(\mathrm{a}_{2}, \mathrm{~b}_{2}, \mathrm{c}_{2}, \mathrm{~d}_{2}\right)$, or BSA $15 \times 10^{-4} \mathrm{~mol} \mathrm{~L}^{-1}\left(\mathrm{a}_{3}, \mathrm{~b}_{3}, \mathrm{c}_{3}, \mathrm{~d}_{3}\right)$. 
Table 1 Stern-Volmer quenching constants $\left(K_{\mathrm{sv}}\right)$ and bimolecular quenching constants $\left(K_{\mathrm{q}}\right)$ for the interaction of pyrazine and bovine serum albumin at 300,310 and $323 \mathrm{~K}$

\begin{tabular}{|c|c|c|c|c|c|c|}
\hline Complex & $T(\mathrm{~K})$ & $K_{\mathrm{sv}}\left(\mathrm{L} \mathrm{mol}^{-1}\right)$ & $K_{\mathrm{q}}\left(\mathrm{L} \mathrm{mol}{ }^{-1} \mathrm{~s}^{-1}\right)$ & $R^{a}$ & $\mathrm{SD}^{b}$ & $\ln K=-\frac{\Delta H}{R T}+\frac{\Delta S}{R} c$ \\
\hline \multirow[t]{3}{*}{ 2-Methylpyrazine } & 300 & $0.61 \times 10^{3}$ & $0.61 \times 10^{11}$ & 0.9548 & 0.0573 & \multirow[t]{3}{*}{$y=1378.3 x+1.8219$} \\
\hline & 310 & $0.53 \times 10^{3}$ & $0.53 \times 10^{11}$ & 0.9837 & 0.0427 & \\
\hline & 323 & $0.44 \times 10^{3}$ & $0.44 \times 10^{11}$ & 0.9192 & 0.0607 & \\
\hline \multirow{3}{*}{ 2,5-Dimethylpyrazine } & 300 & $1.24 \times 10^{3}$ & $1.24 \times 10^{11}$ & 0.9927 & 0.0429 & \multirow{3}{*}{$y=244.81 x+6.3068$} \\
\hline & 310 & $1.17 \times 10^{3}$ & $1.17 \times 10^{11}$ & 0.9934 & 0.0235 & \\
\hline & 323 & $1.17 \times 10^{3}$ & $1.17 \times 10^{11}$ & 0.9918 & 0.0699 & \\
\hline \multirow[t]{3}{*}{ 2,3,5-Trimethylpyrazine } & 300 & $1.67 \times 10^{3}$ & $1.67 \times 10^{11}$ & 0.9935 & 0.0140 & \multirow[t]{3}{*}{$y=101.86 x+7.0807$} \\
\hline & 310 & $1.65 \times 10^{3}$ & $1.65 \times 10^{11}$ & 0.9909 & 0.0185 & \\
\hline & 323 & $1.63 \times 10^{3}$ & $1.63 \times 10^{11}$ & 0.9919 & 0.0199 & \\
\hline \multirow[t]{3}{*}{ 2,3,5,6-Tetramethylpyrazine } & 300 & $6.18 \times 10^{3}$ & $6.18 \times 10^{11}$ & 0.9932 & 0.0044 & \multirow[t]{3}{*}{$y=1296.6 x+4.4289$} \\
\hline & 310 & $5.72 \times 10^{3}$ & $5.72 \times 10^{11}$ & 0.9918 & 0.0114 & \\
\hline & 323 & $4.56 \times 10^{3}$ & $4.56 \times 10^{11}$ & 0.9841 & 0.0205 & \\
\hline
\end{tabular}

${ }^{a}$ The correlation coefficient. ${ }^{b}$ The standard deviation for the $K_{\mathrm{sv}}, n=3 .{ }^{c} y$ represents $\ln K, x$ represents $1 / T$.

interaction process. The energy change in quenching process can be calculated by the slope and intercept of the ratio graph of the quench constant and $1 / T$. In the studied temperature range if the enthalpy change $(\Delta H)$ no significant changes, then its value and that of entropy change $(\Delta S)$ can be determined from van't Hoff equation: ${ }^{54}$
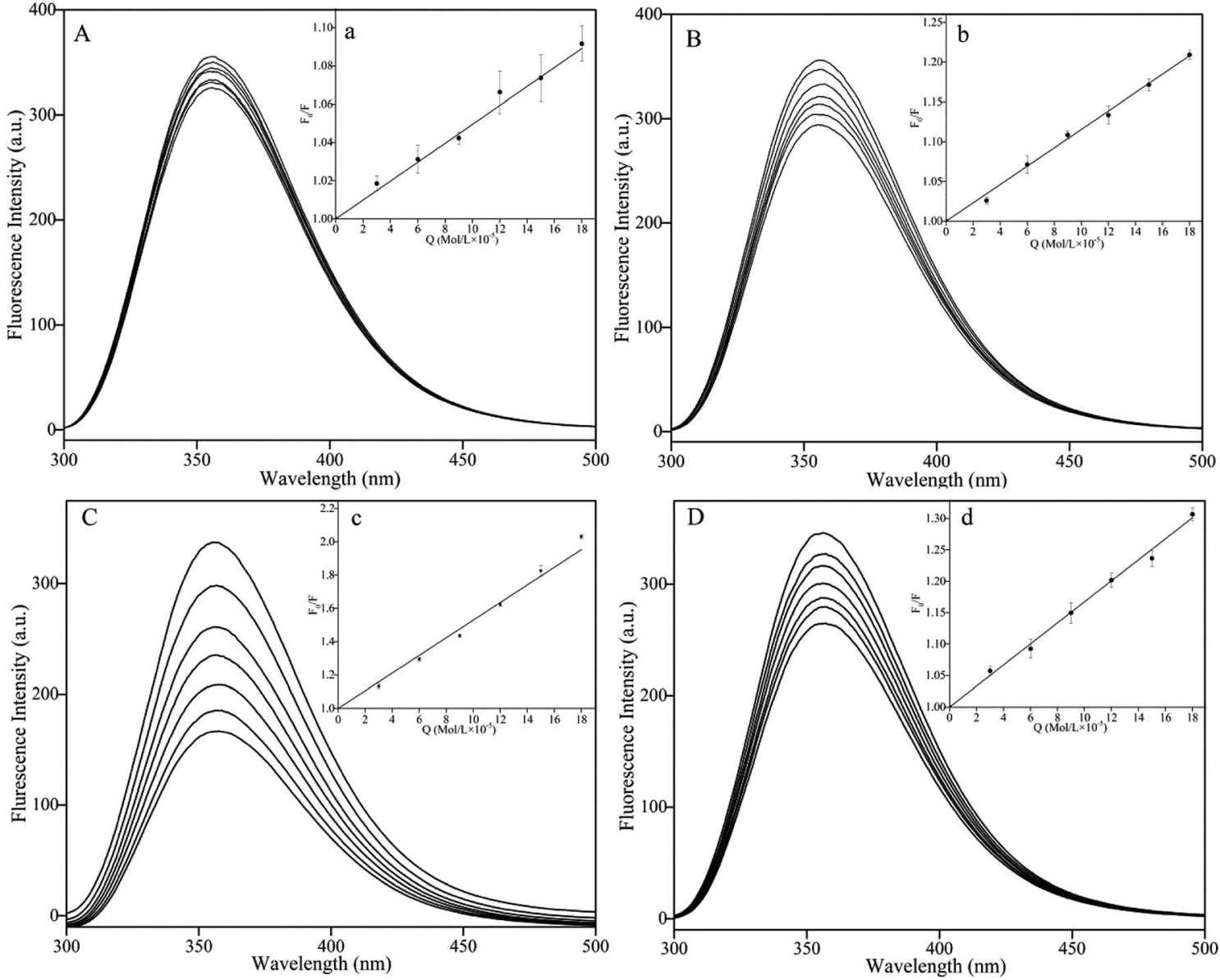

Fig. 3 Fluorescence emission spectra (emission wavelength: from 300 to $500 \mathrm{~nm}$ ) of bovine serum albumin in the presence of various concentrations of 2-methylpyrazine (A), 2,5-dimethylpyrazine (B), 2,3,5-trimethylpyrazine (C) and 2,3,5,6-tetramethylpyrazine (D) at 323 K. The concentration of bovine serum albumin: $5 \times 10^{-4} \mathrm{~mol} \mathrm{~L}^{-1}$, the concentration (from the top to bottom of curves) of pyrazine $=0,3,6,9,12,15$ and $18 \times 10^{-5} \mathrm{~mol} \mathrm{~L}^{-1}$, respectively. The Stern-Volmer plots for the quenching of bovine serum albumin by 2-methylpyrazine (a), 2,5-dimethylpyrazine (b), 2,3,5-trimethylpyrazine (c) and 2,3,5,6-tetramethylpyrazine (d). 


$$
\ln K=-\frac{\Delta H}{R T}+\frac{\Delta S}{R}
$$

where $K$ is the Stern-Volmer quenching constant at the corresponding temperature and $R$ is the gas constant. In addition, the free energy change $(\Delta G)$ can be estimated according to the following relationship:

$$
G=-R T \ln K=\Delta H-T \Delta S
$$

The thermodynamic parameter of the pyrazine-BSA system was listed in Table 1 . The negative enthalpy $(\Delta H)$, positive entropy $(\Delta S)$, and negative free energy $(\Delta G)$ values can be obtained by the slope and intercept of the equations (Table 1 ). The negative sign for $\Delta G$ meant that the interaction process was spontaneous. The negative $\Delta H$ and positive $\Delta S$ values of the interaction of pyrazine and BSA indicate that electrostatic interactions played a major role in the reaction. In addition, the positive $\Delta S$ was taken as evidence for hydrophobic interactions. $^{55}$ Therefore, the major intermolecular interactions between BSA and pyrazines may be electrostatic interactions and hydrophobic interactions.

\section{Microenvironment change}

The change in the synchronous fluorescence spectra was relative to the microenvironment change in fluorophore of protein interacting with ligand, ${ }^{56}$ especially the polarity change of tyrosine $(\Delta \lambda=15 \mathrm{~nm})$ and tryptophan $(\Delta \lambda=60 \mathrm{~nm})$ in protein. ${ }^{57}$ As shown in Fig. 4, the fluorescence intensities of BSA solution at $\Delta \lambda=15 \mathrm{~nm}$ and $\Delta \lambda=60 \mathrm{~nm}$ were decreased with the increasing concentration of pyrazines. Addition of TRP and TEP induced a significant quenching at $\Delta \lambda=15 \mathrm{~nm}$ and $\Delta \lambda=60 \mathrm{~nm}$ compared to the addition of MP and DP. The results confirmed that tyrosine and tryptophan of BSA were contained in the binding sites of BSA and pyrazines. In addition, significant red shifts were observed in Fig. 4(C, D, G and $\mathrm{H})$. The results indicated that BSA conformation had been altered and the hydrophobicity of microenvironment around tyrosine and tryptophan residues both decreased with the increase of concentration of pyrazine,${ }^{\mathbf{5 8 5 9}}$ which meant that the hydrophilicity and polarity of the microenvironment increased. The phenomenon indicated that these amino acid residues were exposed to the solvent at a higher level due to the addition of pyrazine. ${ }^{60}$

\section{Conformational changes}

The UV-vis absorption spectra were widely used to evaluate the structure changes of protein. ${ }^{61}$ As shown in Fig. 5, a strong absorption of BSA at $210 \mathrm{~nm}$ and a weak absorption at $278 \mathrm{~nm}$ were observed. Generally, absorption in the region of 190-240 nm was induced by $n-\pi^{*}$ and $\pi-\pi^{*}$ transition of the amide group, which could be applied to indicate the conformational change of protein. ${ }^{62}$ A significant decrease at $A_{210} \mathrm{~nm}$ indicated that pyrazines may affect the steric structure of BSA when pyrazines were added into BSA solution. The result was consistent with that of synchronous fluorescence.

The value of $A_{278} \mathrm{~nm}$ indicated the polarity of the microenvironment of tryptophan and tyrosine resides could be used to reflect the change in the tertiary structure of protein. ${ }^{63,64}$ As shown in Fig. $5 \mathrm{~A}$ and $\mathrm{B}$, the $A_{278} \mathrm{~nm}$ value of BSA increased with addition of MP and DP and a blue shift of the UV spectra was observed. However, the $A_{278} \mathrm{~nm}$ value of BSA decreased with addition of TRP and TEP and a red shift of the UV spectra was detected (Fig. 5C and D). The results demonstrated that the addition of the pyrazines induced the change in polarity microenvironment of BSA. ${ }^{65}$
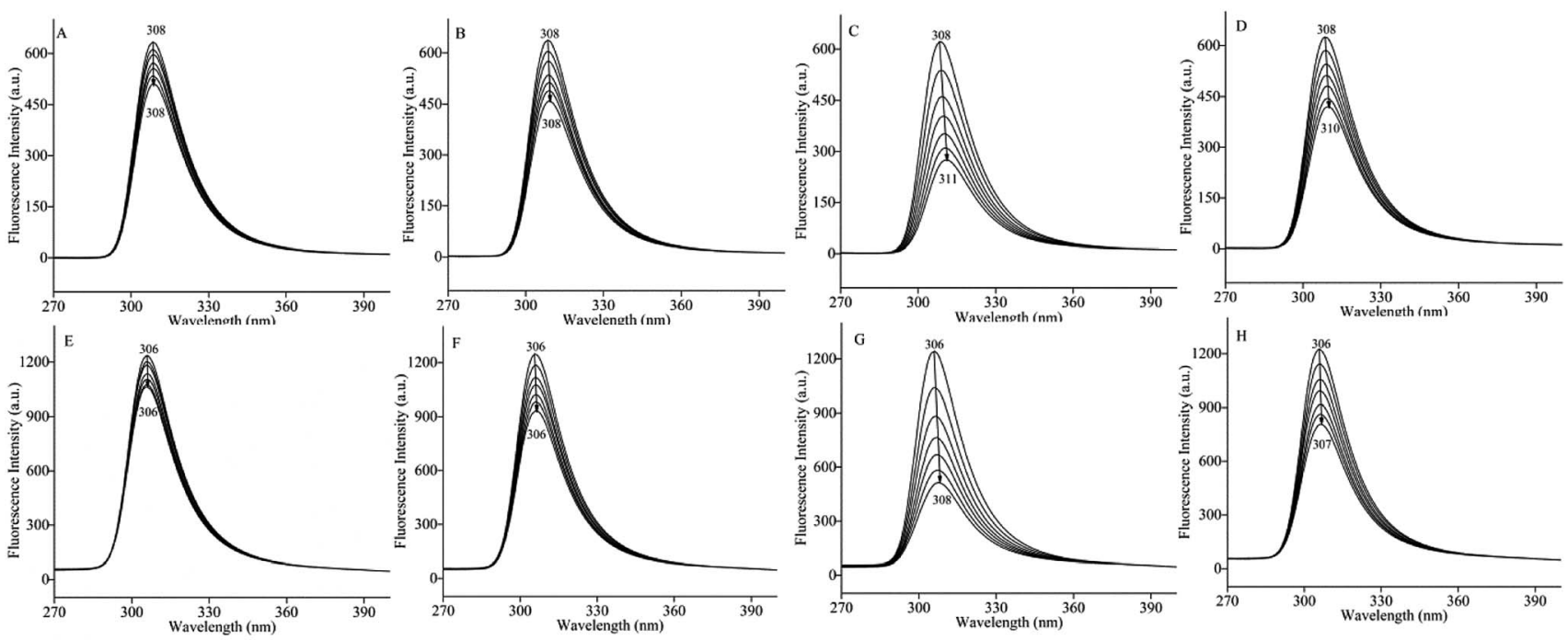

Fig. 4 Synchronous fluorescence spectra of bovine serum albumin in presence of various concentrations of 2-methylpyrazine (A and E), 2,5dimethylpyrazine (B and F), 2,3,5-trimethylpyrazine ( $\mathrm{C}$ and $\mathrm{G})$ and 2,3,5,6-tetramethylpyrazine $(\mathrm{D}$ and $\mathrm{H})$ at $323 \mathrm{~K}$. The concentration of bovine serum albumin: $5 \times 10^{-4} \mathrm{~mol} \mathrm{~L}^{-1}$, the concentration (from top to bottom) of pyrazine $=0,3,6,9,12,15$ and $18 \times 10^{-5} \mathrm{~mol} \mathrm{~L}-1,(\mathrm{~A}-\mathrm{D}) \Delta \lambda=15 \mathrm{~nm}$ and $(\mathrm{E}-\mathrm{H}) \Delta \lambda=60 \mathrm{~nm}$. 

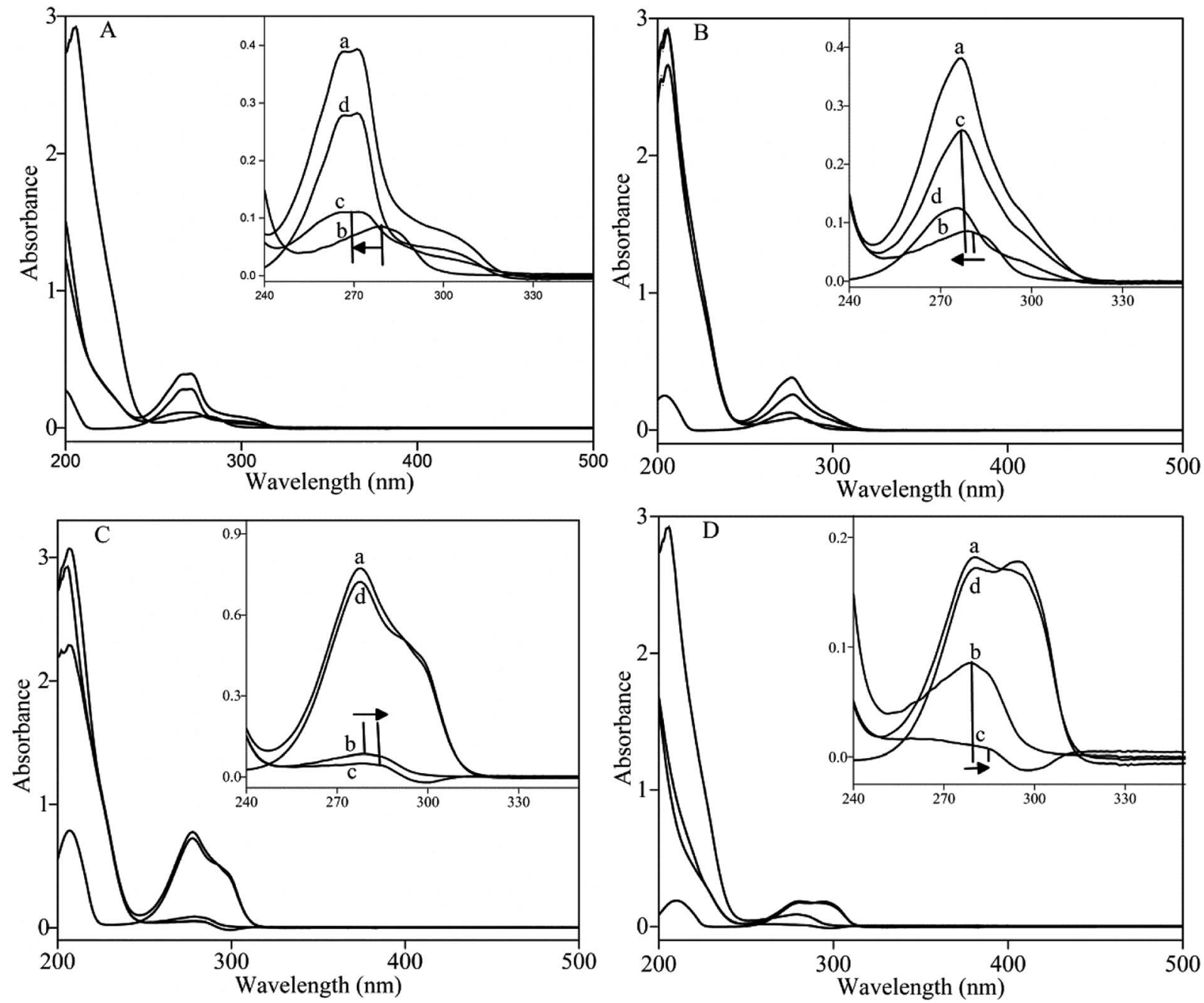

Fig. 5 Ultraviolet visible spectra of adding 2-methylpyrazine (A), 2,5-dimethylpyrazine (B), 2,3,5-trimethylpyrazine (C) and 2,3,5,6-tetramethylpyrazine (D) into bovine serum albumin solution, a: bovine serum albumin and pyrazine, b: bovine serum albumin solution, c: the absorption spectrum of bovine serum albumin and pyrazine subtraction by the spectrum of the pyrazine, $d$ : pyrazine solution. The concentration of bovine serum albumin: $2 \times 10^{-6} \mathrm{~mol} \mathrm{~L}^{-1}$, the concentration of pyrazine: $5 \times 10^{-5} \mathrm{~mol} \mathrm{~L}^{-1}$.

\section{Secondary structure changes}

The CD spectra could directly reflect the secondary structure change of protein. ${ }^{66}$ In this study, CD spectra were carried out at room temperature $(T=300 \mathrm{~K})$ to further reveal the changes of secondary structure of BSA interacted with pyrazines. The CD spectra presented two negative bands at around 208 and $220 \mathrm{~nm}$ (Fig. 6), which were the characteristic of helix and beta structure in the second structure of BSA according to the previous literatures. ${ }^{67}$ As shown in Table 2, the helix of BSA with the addition of pyrazines decreased from 59.03 to $53.17 \%$. A possible reason could be explained that pyrazines attacked amino acid residues in the main polypeptide chain of BSA and destroyed their hydrogen bond network. ${ }^{60}$ Interestingly, the random of BSA with the addition of pyrazines had no significant changes. However, the turns of BSA presented a significant increase (from 2.97 to 9.27\%) with addition of MP, DP, TRP and TEP. Obviously, the addition of pyrazines could induce the secondary structure change of BSA, which could be related to the change of pyrazines release in BSA solution.

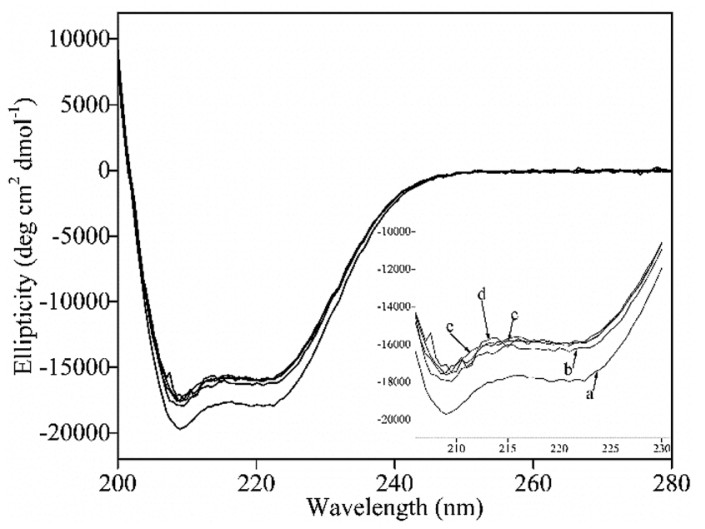

Fig. 6 Circular dichroism spectra of bovine serum albumin (a), bovine serum albumin and 2-methylpyrazine (b), bovine serum albumin and 2,5-dimethylpyrazine (c), bovine serum albumin and 2,3,5,6-tetramethylpyrazine (d) and 2,3,5,6-tetramethylpyrazine (e), the concentration of bovine serum albumin: $5 \times 10^{-6} \mathrm{~mol} \mathrm{~L}^{-1}$, the concentration of pyrazine: $1 \times 10^{-4} \mathrm{~mol} \mathrm{~L}^{-1}$. 
Table 2 Secondary structure of bovine serum albumin without and with the addition of pyrazine at $300 \mathrm{~K}^{a}$

\begin{tabular}{|c|c|c|c|c|}
\hline Complex & Helix (\%) & Beta $(\%)$ & Turn (\%) & Random (\%) \\
\hline 2-Methylpyrazine & $53.20 \pm 0.03^{\mathrm{b}}$ & $11.20 \pm 0.19^{\mathrm{a}}$ & $8.03 \pm 0.29^{b}$ & $27.53 \pm 0.03^{\mathrm{a}}$ \\
\hline 2,3,5-Trimethylpyrazine & $53.73 \pm 0.01^{\mathrm{b}}$ & $9.67 \pm 0.18^{\mathrm{a}}$ & $9.27 \pm 0.09^{b}$ & $26.33 \pm 0.07^{\mathrm{a}}$ \\
\hline 2,3,5,6-Tetramethylpyrazine & $53.17 \pm 0.04^{\mathrm{b}}$ & $13.70 \pm 0.17^{\mathrm{a}}$ & $7.17 \pm 0.42^{\mathrm{b}}$ & $26.00 \pm 0.04^{\mathrm{a}}$ \\
\hline
\end{tabular}

${ }^{a}$ Average \pm standard deviations, $n=3$. Different letters in the same column indicate significant differences $(p<0.05)$.

\section{Conclusion}

The methyl distribution of pyrazines had a significant effect on the pyrazines release from BSA solution, which was mainly due to electrostatic interaction and hydrophobic interaction. The interaction between pyrazines homologues (MP, DP, TRP, and TEP) and BSA revealed that non-covalent interaction presented in BSA-pyrazine systems, which induced the difference release pattern of pyrazines in BSA solution. The disclosed mechanism of pyrazines release was helpful for the flavor compounds analysis and the control of flavor release in food matrix.

\section{Conflicts of interest}

There are no conflicts to declare.

\section{Abbreviations}

$\begin{array}{ll}\text { MP } & \text { 2-Methylpyrazine } \\ \text { DP } & \text { 2,5-Dimethylpyrazine } \\ \text { TRP } & \text { 2,3,5-Trimethylpyrazine } \\ \text { TEP } & \text { 2,3,5,6-Tetramethylpyrazine } \\ \text { BSA } & \text { Bovine serum albumin } \\ \text { CD } & \text { Circular dichromatic } \\ \text { UV-vis } & \text { Ultraviolet visible } \\ \text { PBS } & \text { Phosphate buffer solution } \\ \text { SPME-GC- } & \text { Solid phase micro-extraction gas chromatography } \\ \text { MS } & \text { mass spectrometry } \\ \text { EX } & \text { Excitation } \\ \text { EM } & \text { Emission }\end{array}$

\section{Acknowledgements}

This work was supported by the 13th Five Years Key Programs for Science and Technology Development of China (Grant No. 2017YFD0400103) and the National Natural Science Foundation of China (Grant No. 31871795; 31601467).

\section{References}

1 K. Wang and S. D. Arntfield, Flavour Fragrance J., 2017, 32, 92-101.

2 S. Lubbers, P. Landy and A. Voilley, Food Technol., 1998, 52, 68-74.
3 K. B. D. Roos, in Physiochemical Models of Flavor Release from Foods, ed. D. D. Roberts and A. J. Taylor, ACS Publications, 2000, p. 126.

4 P. Relkin, M. Fabre and E. Guichard, J. Agric. Food Chem., 2004, 52, 6257-6263.

5 X. Liu, J. R. Powers, B. G. Swanson, H. H. Hill and S. Clark, J. Food Sci., 2010, 70, C581-C585.

6 E. Guichard, Food Rev. Int., 2002, 18, 49-70.

7 S. Ghosh, D. G. Peterson and J. N. Coupland, J. Agric. Food Chem., 2006, 54, 1829-1837.

8 S. Karaiskou, G. Blekas and A. Paraskevopoulou, Food Res. Int., 2008, 41, 637-645.

9 A. Meynier, C. Lecoq and C. Genot, Food Chem., 2005, 93, 153-159.

10 A. H. King, in Encapsulation of food ingredients: a review of available technology, focusing on hydrocolloids, ed. S. J. Rish and G. A. Reineccius, ACS Publications, 1995, p. 26.

11 T. A. Tari and R. S. Singhal, Carbohydr. Polym., 2002, 50, 279282.

12 A. Madene, M. Jacquot, J. l. Scher and S. Desobry, Int. J. Food Sci. Technol., 2010, 41, 1-21.

13 B. Lin, F. Zhang, T. Chen, J. Cao, Y. Chen and Y. Bai, Flavour Fragrance J., 2015, 30, 459-466.

14 L. Mao, Y. H. Roos, C. G. Biliaderis and S. Miao, Crit. Rev. Food Sci. Nutr., 2017, 57, 3173-3187.

15 Z. Xiao, T. Tian, J. Hu, M. Wang and R. Zhou, Flavour Fragrance J., 2014, 29, 22-34.

16 J. Kühn, T. Considine and H. Singh, J. Food Sci., 2006, 71, R72-R82.

17 K. Wang and S. D. Arntfield, Food Chem., 2014, 157, 364-372.

18 H. Shen, M. Zhao and W. Sun, Food Chem., 2019, 287, 93-99.

19 T. E. O'Neill and J. E. Kinsella, J. Food Sci., 1987, 52, 98-101.

20 F. Zhou, M. Zhao, G. Su and W. Sun, J. Agric. Food Chem., 2014, 62, 9544-9552.

21 Y. Tan and K. J. Siebert, J. Food Sci., 2010, 73, S56-S63.

22 M. PéRezjuan, M. Flores and F. Toldra, Food Chem., 2007, 105, 932-939.

23 M. Pérez-Juan, M. Flores and F. Toldrá, J. Agric. Food Chem., 2006, 54, 4802-4808.

24 H.-I. Hwang, T. G. Hartman and C.-T. Ho, J. Agric. Food Chem., 1995, 43, 179-184.

25 M. Amrani-Hemaimi, C. Cerny and L. B. Fay, J. Agric. Food Chem., 1995, 43, 2818-2822.

26 I. Besson, C. Creuly, J. B. Gros and C. Larroche, Appl. Microbiol. Biotechnol., 1997, 47, 489-495. 
27 C. Larroche, I. Besson and J.-B. Gros, Process Biochem., 1998, 34, 667-674.

28 T. Shibamoto, T. Akiyama, M. Sakaguchi, Y. Enomoto and H. Masuda, J. Agric. Food Chem., 1979, 27, 1027-1031.

29 R. Wagner, M. Czerny, J. Bielohradsky and W. Grosch, Z. Lebensm.-Unters. -Forsch. A, 1999, 208, 308-316.

30 A. Tromelin and E. Guichard, J. Agric. Food Chem., 2003, 51, 1977-1983.

31 E. A. Foegeding and J. P. Davis, Food Hydrocolloids, 2011, 25, 1853-1864.

32 L.-y. Yin, X.-g. Zhou, J.-s. Yu, H.-l. Wang, S. Zhao, Z. Luo and B. Yang, J. Eur. Ceram. Soc., 2013, 33, 1387-1392.

33 E. Guichard, Biotechnol. Adv., 2006, 24, 226-229.

34 J. Kühn, T. Considine and H. Singh, J. Agric. Food Chem., 2008, 56, 10218-10224.

35 J. Kühn, X.-Q. Zhu, T. Considine and H. Singh, J. Agric. Food Chem., 2007, 55(9), 3599-3604.

36 H. Jegasothy, L. Bennett and R. Stockmann, Int. Dairy J., 2015, 47, 46-51.

37 C. Semasaka, L. Katopo, R. Buckow and S. Kasapis, Food Hydrocolloids, 2018, 76, 141-149.

38 J. Zhu, X. Sun, S. Wang, Y. Xu and D. Wang, Food Hydrocolloids, 2017, 63, 391-403.

39 J. Y. Jun, H. H. Nguyen, S.-Y.-R. Paik, H. S. Chun, B.-C. Kang and S. Ko, Food Chem., 2011, 127, 1892-1898.

40 K.-Y. Park, D.-Y. Kim and W.-S. Shin, Food Sci. Biotechnol., 2015, 24, 1583-1589.

41 F. Liu, J. Zheng, C.-H. Huang, C.-H. Tang and S.-Y. Ou, Food Hydrocolloids, 2018, 82, 96-105.

42 O. Becconi, E. Ahlstrand, A. Salis and R. Friedman, Isr. J. Chem., 2017, 57, 403-412.

$43 \mathrm{~J} . \mathrm{Li}$ and P. Yao, Langmuir, 2009, 25, 6385.

44 Y. D. Livney, in Biopolymeric amphiphiles and their assemblies as functional food ingredients and nutraceutical delivery systems, ed. N. Garti and J. Mcclements, Woodhead Publishing Limited: 80 High Street, Cambridge, 2012, p. 252.

45 K. G. Weel, A. E. Boelrijk, A. C. Alting, P. J. Van Mil, J. J. Burger, H. Gruppen, A. G. Voragen and G. Smit, J. Agric. Food Chem., 2002, 50, 5149-5155.

46 S. Damodaran and J. E. Kinsella, J. Agric. Food Chem., 1980, 28, 567 .

47 F. M. Gianelli M P and F. Toldrá, J. Agric. Food Chem., 2003, 51, 6828-6834.

48 A. Papadopoulou, R. J. Green and R. A. Frazier, J. Agric. Food Chem., 2005, 58, 158-163.
49 H. Mohammadzadeh-Aghdash, J. Ezzati Nazhad Dolatabadi, P. Dehghan, V. Panahi-Azar and A. Barzegar, Food Chem., 2017, 228, 265-269.

50 S. Huang, H. Qiu, J. Xie, C. Huang, W. Su, B. Hu and Q. Xiao, RSC Adv., 2016, 6, 44531-44542.

51 J. R. Lakowicz, in Principles of fluorescence spectroscopy, Woodhead Publishing Limited: Springer Science+Business Media, New York, 1999.

52 D. Leckband, Annu. Rev. Biophys. Biomol. Struct., 2003, 29, 126.

53 G. Li, B. S. Liu, Q. Zhang and R. Han, Luminescence, 2016, 31, 1054-1062.

54 Y. J. Hu, L. Yi, J. B. Wang, X. H. Xiao and S. S. Qu, J. Pharm. Biomed. Anal., 2005, 36, 915-919.

55 B. Pang, S. Bi, Y. Wang, L. Yan and T. Wang, J. Lumin., 2012, 132, 895-900.

56 Y. J. Hu, Y. Liu, T. Q. Sun, A. M. Bai, J. Q. Lu and Z. B. Pi, Int. J. Biol. Macromol., 2006, 39, 280-285.

57 Y. Q. Wang, H. M. Zhang, G. C. Zhang, S. X. Liu, Q. H. Zhou, Z. H. Fei and Z. T. Liu, Int. J. Biol. Macromol., 2007, 41, 243250.

58 N. Wang, L. Ye, B. Q. Zhao and J. X. Yu, Braz. J. Med. Biol. Res., 2008, 41, 55-60.

59 Z. Nan, C. Hao, X. Ye, Y. Feng and R. Sun, Spectrochim. Acta, Part A, 2019, 210, 348-354.

60 H. Shen, M. Huang, M. Zhao and W. Sun, Food Chem., 2019, 298, 125060.

61 K. Nienhaus and G. U. Nienhaus, in Probing Heme ProteinLigand Interactions by UV/Visible Absorption Spectroscopy, ed. G. U. Nienhaus, Woodhead Publishing Limited: Humana Press, 2005, p. 251.

62 A. N. Glazer and E. L. Smith, J. Biol. Chem., 1961, 236, 29422947.

63 K. Rosenheck and P. Doty, Proc. Natl. Acad. Sci. U. S. A., 1961, 47, 1775-1785.

64 D. Li, B. Ji and J. Jin, J. Lumin., 2008, 128, 1399-1406.

65 Y. Zhang and Q. Zhong, J. Agric. Food Chem., 2012, 60, 18801886.

66 S. M. Darwish, S. E. Abu sharkh, M. M. Abu Teir, S. A. Makharza and M. M. Abu-hadid, J. Mol. Struct., 2010, 963, 122-129.

67 J. Liu, J. Tian, X. Tian, Z. Hu and X. Chen, Bioorg. Med. Chem., 2004, 12, 469-474. 